\title{
Automatic Voltage Regulator (AVR) Controller Design Based on Routh's Crution Stability Analysis in Diesel-Based Power Plants
}

\author{
Paulus Mangera ${ }^{1}$, Frederik Hariyanto Sumbung ${ }^{2}$ \\ Electrical Engineering Department \\ Universitas Musamus \\ Merauke, Indonesia \\ 1paulus@unmus.ac.id, ${ }^{2}$ frederik@unmus.ac.id
}

\author{
Daniel Parenden ${ }^{3}$ \\ Mechanical Engineering Department, \\ Universitas Musamus \\ Merauke, Indonesia \\ 3aniel@unmus.ac.id
}

\begin{abstract}
Changes in load on electric power systems are unavoidable at all times. But the increase in load that is not accompanied by additional capacity will cause the system to operate abnormally. The normal or abnormal condition of the power system leads to electrical voltage problems. Excessive reactive power can damage the generator stator windings due to increased stator currents. Increased stator current can be overcome by increasing the generator voltage. In order for this incident to not occur, an AVR can be used to adjust the generator voltage according to the increase in reactive power. Automatic Voltage Regulator (AVR) Controller Design Analysis using Matlab program with simulink method using Routh's Criteria. Matlab programming simulation results and Routh's criteria analysis showed that the PID controller was able to reduce oscillations occured and the system quickly returned to a stable condition even though there was a change in load (interference) by adjusting the $\mathbf{P}$ (proportional), I (integrative) and $D$ (devirative) parameters. In this case, the AVR performance was changed by setting the root value in the characteristic equation so that the constants $\mathrm{Kp}=\mathbf{0 . 0 1 6 1 3 5}, \mathrm{Ki}=\mathbf{0 . 0 1 8 1 5}$ and $\mathrm{Kd}=\mathbf{0 . 0 0 3 5 9}$ were obtained. This value was able to maintain the generator voltage output at the time of interference with settling time (ts) of $\mathbf{0 . 8 9 5 9 4}$ and maximum overshoot of $25 \%$.
\end{abstract}

Keywords: PID; AVR; Excitation; Generators; Sensors

\section{INTRODUCTION}

Automatic control has played a very important role in the development of science and technology. This is only found in many industries such as factories and modern industries. For example, automatic control is indispensable in operations in the industry for controlling pressure, temperature, humidity, viscosity, production process flow, work with machine tools, handling and assembling mechanical parts in the manufacturing industry, and so on. Because progress in the theory and practice of automatic control provides convenience in obtaining performance from dynamic systems, enhances quality and lowers production costs, enhances the rate of production, eliminates routine and tedious work that must be carried out by humans, and so on.

Likewise with the operation of the power system, especially the large-scale power system normally in the control area can be expressed in groups from the existing generator. Changes in load and abnormal conditions cause changes in frequency and power scheduling in each area. Changes like this result in changes in voltage magnitude. This can be fatal in a system if there is an increase in the reactive power load because the generator terminal voltage will decrease. To overcome this, it is used to control generator excitation using the AVR (Automatic Voltage Regulator) with the basic principle that the AVR is able to maintain the amount of voltage in the event of an interruption or change in load in the system.[1]

In fact, when the Generator is operated (at a frequency of 50 $\mathrm{Hz}$ with a fixed voltage output quantity), the Generator will rotate at a relatively constant speed. However, the generator rotation speed is affected by the load. When the load increases, the speed will decrease, and vice versa. This has been an obstacle for AVR in maintaining voltage. Therefore, if we expect the Generator to be operated at a constant speed when the load changes, a controller is needed to adjust the input voltage frequency. With the development of the usefulness of computer technology, software is made that can support all fields, especially in the field of electricity. One of these software is MATLAB which can be used to simulate and analyze a device without touching the equipment. It is even able to display the response of an equipment when input is given and if the input is changed.[2]

\section{LITERATURE REVIEW}

\section{A. Automatic Voltage Regulator (AVR)}

The rule of AVR is to maintain the voltage level of the generator terminal at the specified level. The AVR system consists of four (4) main components, namely: Amplifier, Exciter, Generator and Sensor.[3] Mathematical models and transfer functions of the four components are shown below:

1) Amplifier model: The Amplifier model is expressed by a gain with the symbol of $\mathrm{K}_{\mathrm{A}}$ and a time constant with the symbol of $\tau_{\mathrm{A}}$. The transfer function is:

$$
\frac{V R(S)}{V e(s)}=\frac{K_{A}}{1+\tau_{A} S}
$$


With:

$\mathrm{K}_{\mathrm{A}}$ value ranged between $10-400$

Time constant $\tau_{\mathrm{A}}$ ranged between $0.02-0.1$ second

2) Exciter model: The transfer function of modern Exiter can be expressed by a gain with the symbol of $\mathrm{K}_{\mathrm{E}}$ and a single time constant with the symbol $\tau_{\mathrm{E}}$, the transfer function is:

$$
\frac{V F(s)}{V R(s)}=\frac{K_{E}}{1+\tau_{E} s}
$$

With :

$\mathrm{K}_{\mathrm{E}}$ value ranged between $10-400$

Time constant $\tau_{\mathrm{E}}$ ranged between $0.5-1$ second.

3) Generator Model: In a linearized model, the relationship between the generator terminal voltage transfer function and the field voltage can be expressed by a Gain $\left(\mathrm{K}_{\mathrm{G}}\right)$ and time constant $\left(_{\mathrm{G}}\right)$. Thus the function transfer is:

$$
\frac{V t(s)}{V F(s)}=\frac{K_{G}}{1+\tau_{G} s}
$$

This constant depends on the load, which can vary between $0.7-1.0$ and between 1.0 and 2.0 from full load to zero load.

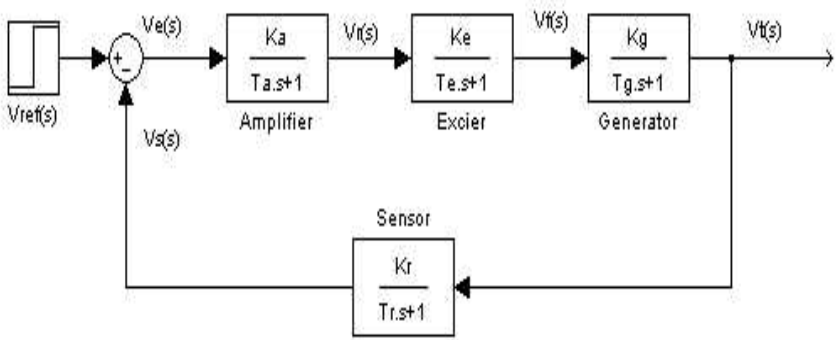

Fig. 1. AVR system block diagram

4) Sensor model: The sensor is modeled with a simple first order transfer function that is written as:

$$
\frac{V s(s)}{V t(s)}=\frac{K_{G}}{1+\tau_{G} s}
$$

With:

$\tau_{\mathrm{G}}$ value ranged between 0.001 to 0.06 second

Picture of automatic voltage regulator (AVR) model can be seen in Figure 2.1 below:

\section{B. PID Controller.}

Proportional-Integral-Derivative Controllers are chosen for this system because they are reliable enough to overcome large and sudden load changes. Integral mode is used to eliminate proportional offsets and derivative modes are used to reduce the tendency to oscillations and provide control actions that anticipate changes in error signals.[4] The implementation of PID controllers in a computer is as follows:
1) Proportional mode: Proportional mode is implemented on a computer with the same equation as the analog equation, namely:

$$
P=K_{P} \times E
$$

With :

$\mathrm{P}$ : proportional controller output

$\mathrm{K}_{\mathrm{P}}$ : proportional gain

$\mathrm{E}$ : error signal

2) Integral mode: We need a way to calculate integral error signals in using this mode. There are many algorithms developed, all of which are only approximations/approaches because only samples of error signals are available. The simplest method is called square, and this method is accurate enough to be used in control. The equation for calculating error integration is:

$$
\int_{0}^{t} e_{P} d t \approx\left[S+e_{p i}\right] \Delta t
$$

With:

$\Delta \mathrm{t}$ : time between samples,

$\mathrm{S}=\mathrm{ep}_{1}+\mathrm{ep}_{2}+\ldots .:$ the number of error signals calculated before the sample variable,

$\mathrm{e}_{\mathrm{pi}}$ : the last sample taken at time $\mathrm{t}$ specified in the integral limit.

The smaller the time between samples, the results will be closer to the actual results. The implementation of this mode in a computer is done by the equation:

$$
\begin{gathered}
S U M=S U M+E \\
P I=K I \times D T \times S U M
\end{gathered}
$$

With:

SUM :number of error signals,

KI : integral gain,

DT : time between samples.

Because KI*DT is a multiplying factor for SUM, both of which are often combined into KI only, so that the above equation can be simplified to:

$$
P I=K I \times S U M .
$$

3) Derivative mode: This mode is implemented in computer control by calculating the derivative approach of the error signal from the data sample. A derivative is defined as the speed at which quantity changes over the sample period of $\Delta t$, therefore, this is only an approach. The equation:

$$
d \frac{e_{p i}}{d t} \approx \frac{e_{p i}-e_{p i-1}}{\Delta t}
$$

With:

$\mathrm{e}_{\mathrm{pi}} \quad$ : current error signal samples

$\mathrm{e}_{\mathrm{pi}-1} \quad$ : previous error signal samples

$\Delta \mathrm{t} \quad$ : time between samples.

In the computer, the above equation becomes:

$D E=E-E 0$

$E 0=E$

$P D=K D \times D E / D T$ 
With:

DE: error signal derivation,

E : current error signal,

$\mathrm{E}_{0}$ : previous error signal,

$\mathrm{KD}$ : derivative gain.

Because KD/DT is a multiplier of DE, both are often combined into $\mathrm{KD}$ only so that the above equation can be simplified to:

$$
P D=K D \times D
$$

The PID controller is a type of continuous controller that is composed of three basic continuous controller types, namely Proportional controllers, Integral controllers and Differential controllers. Mathematically, PID controllers can be written as:

$$
m(t)=K_{p} e(t)+K_{I} \int_{0}^{t} e(t) d t+K_{D} \frac{d e(t)}{d t}
$$

With:

$\mathrm{mIt})=$ input compensator

$\mathrm{e}(\mathrm{t})=$ output compensator

From the Laplace transformation of the above equation, the PID controller transfer function is obtained as follows:

$$
M(s)=\left(K_{p}+\frac{K_{I}}{S}+K_{D} s\right) E(s)
$$

With :

$\mathrm{K}_{\mathrm{P}}=$ proportional reinforcement constant

$\mathrm{K}_{\mathrm{I}}=$ integral reinforcement constants

$\mathrm{K}_{\mathrm{D}}=$ differential reinforcement constants

Mathematical equations for PID controllers arranged in parallel can be expressed in the form of block diagrams as shown below:

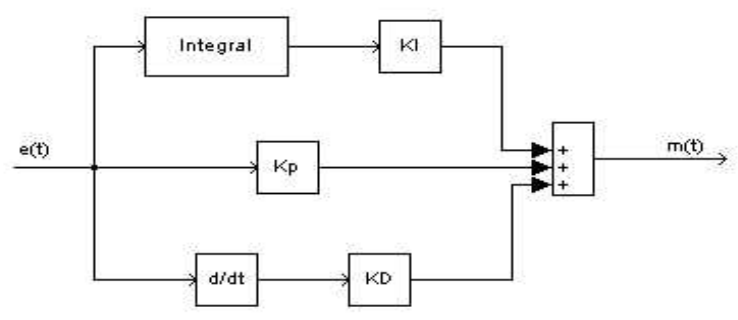

Fig. 2. Mathematical PID block diagram

Whereas the form of the Laplace PID controller equation arranged in parallel can be expressed in the form of a block diagram as shown below:

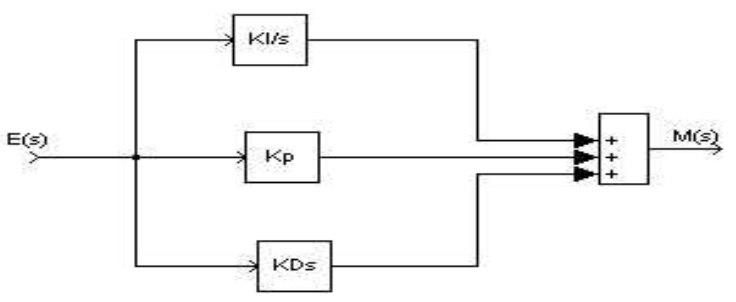

Fig. 3. Block diagram of PID with Laplace

\section{PID Controller Performance}

To show the performance of PID, the system response will be compared when using proportional-only, proportionalintegral, and proportional-integral-derivative modes.

Proportional mode with $\mathrm{Kp}=3.0$ produces a large offset. Offset occurs because the resulting error signal is too small to increase output. If $\mathrm{Kp}$ is raised, for example to 9.0, oscillation will occur, and the output is still not large enough to make the speed reach the setpoint. If $\mathrm{Kp}$ is enlarged again until the setpoint can be reached, the oscillation will be even greater. The existence of oscillations and offsets is indeed a weakness of proportional controllers because this controller will only produce output if there is an error signal, and if the error signal is too small, this signal is no longer able to control the controlled variable.

Integral mode is added to eliminate offset. If there is an error signal, the integrator tends to increase the control action towards the desired output. If the error signal disappears (zero) then a continuous and constant integrator output is used to keep the control action in steady state.

Derivative mode is used to speed up the system dynamic response. Derivative mode anticipates the error signal that will occur by observing the rate of error change. Derivative mode reduces the tendency towards oscillation and is useful especially if the process has a sudden change in load.[4]

\section{Steady-State Errors}

A commonly used formulation for analyzing steady state errors uses the open loop transfer function or close loop transfer function, with feedback equal to one (unity).[5] Example of system:

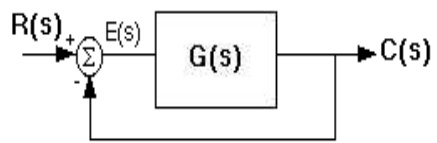

Fig. 4. Equation diagram block I

or:

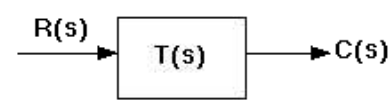

Fig. 5. Equation diagram block II

To calculate the steady state error for the system above from the open loop transfer function or close loop transfer, we use the final value theorem, namely:

$$
\begin{gathered}
e(\infty)=\lim _{s \rightarrow 0} \frac{s R(s)}{1+G(s)} \\
e(\infty)=\lim _{s \rightarrow 0} s R(s)[1-T(s)]
\end{gathered}
$$

Laplace transformation for different inputs and obtain the equation to solve the steady state error of the open loop transfer function. For example: given a different input as follows: 
a. Step $\operatorname{Input}(R(s)=1 / s)$ :

$$
e(\infty) \frac{1}{\lim _{s \rightarrow 0} G(s)}=\frac{1}{1+K_{P}} \Rightarrow K_{P}=\lim _{s \rightarrow 0} G(s)
$$

b. $\operatorname{Ramp} \operatorname{Input}\left(R(s)=1 / s^{\wedge} 2\right)$ :

$$
e(\infty) \frac{1}{\lim _{s \rightarrow 0} s G(s)}=\frac{1}{K_{P}} \rightarrow K_{P}=\lim _{s \rightarrow 0} s G(s)
$$

c. Parabolic Input $\left(R(s)=1 / s^{\wedge} 3\right)$ :

$$
e(\infty) \frac{1}{\lim _{s \rightarrow 0} s^{2} G(s)}=\frac{1}{K_{P}} \rightarrow K_{P}=\lim _{s \rightarrow 0} s^{2} G(s)
$$

The controller design is usually compensated for system errors. Here is the circuit:

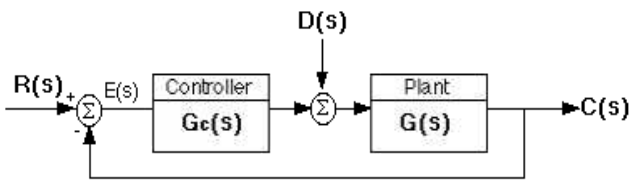

Fig. 6. Block diagram of PID with Laplace

Steady state error is obtained to input an error step with the following equation:

$$
e(\infty)=\frac{1}{\lim _{s \rightarrow 0} \frac{1}{G(s)}+\lim _{s \rightarrow 0} G(s)}
$$

We will first complete the steady state error for a system with feedback that is not the same as one (non unity):

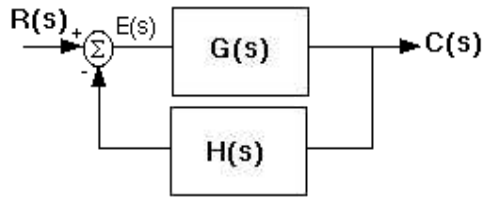

Fig. 7. Steady-State Errors block diagram for systems with feedback

With block multiplication, the system model becomes:

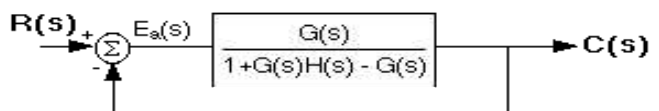

Fig. 8. Block diagram of Steady-State Errors with block multiplication

\section{RESEARCH METHODOLOGY}

The analytical method used in this study was an analytical method to get the PID constant then simulated it with Simulink in Matlab. The analytic results were then tested with simulink in Matlab to see the graph of generator output voltage due to changes in system load either by proportional Scontrol (P) or by a proportional integral derivative (PID) controller optimum design.

\section{RESUlTS AND DisCUSSION}

\section{A. Research Result Data}

At this Ssangyong plant, using a three-phase synchronous generator, the data from the PLTD MAN (Diesel Power Plant) generator are as follows:

Name Plate: 2 poles, 3 phase, WYE connected, $50 \mathrm{~Hz}, 750 \mathrm{rpm}$.

TABLE I. CHARACTERISTIC DATA OF PLTD SSANGYONG GENERATORS

\begin{tabular}{|l|l|l|}
\hline \multicolumn{1}{|c|}{ Description } & \multicolumn{1}{c|}{ Ratings } & \multicolumn{1}{c|}{ Peak } \\
\hline Output Power & $1250 \mathrm{KVA}$ & $1250 \mathrm{KVA}$ \\
\hline Armature Current & $114.6 \mathrm{~A}$ & $114.6 \mathrm{~A}$ \\
\hline Armature Voltage & $6.3 \mathrm{KV}$ & $6.3 \mathrm{KV}$ \\
\hline Field Ampere & $4: 00 \mathrm{AM}$ & $4: 00 \mathrm{AM}$ \\
\hline Voltage Reference & $110 \mathrm{~V}$ & - \\
\hline Exciter Volts & $56.3 \mathrm{~V}$ & $56.3 \mathrm{~V}$ \\
\hline Power Factor & 0.8 & 0.8 \\
\hline
\end{tabular}

Source: PT. PLN (Persero) Merauke P2B Area

\section{B. AVR SIMULATION ON PLTD}

1) AVR system with Proportional Controller $(P)$

Normal Condition (Change in Voltage $=0$ due to Reactive Power Change $=0$ )

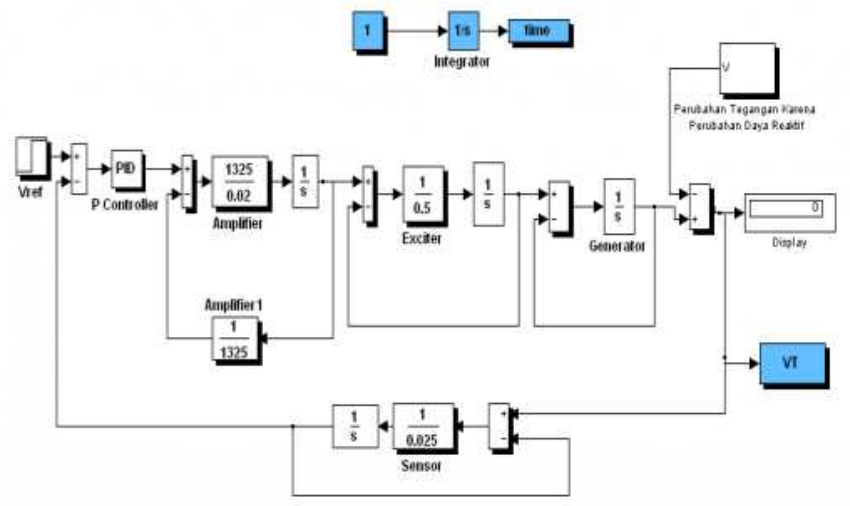

Fig. 9. Simulation of AVR with Proportional Control under Normal Conditions (Change in Voltage $=0$ because of Reactive Power Change $=0$ )

The parameter value of KP is calculated by the Routh Stability Criteria in determining the stability of the system with the following steps:

Simplifying Figure 9 above in the form of the following closed block diagram:

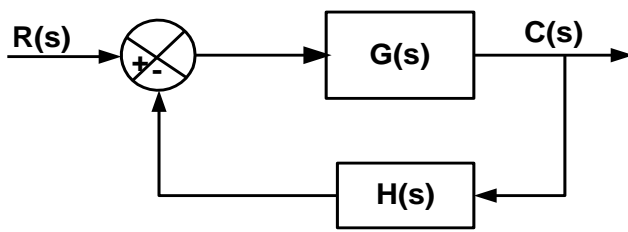

Fig. 10. Simplification of block diagrams in Figure 9 
Simulation Results from Calculation results of Range Parameter (Kp)

a) For $\mathrm{Kp}=-0.0007:$ For $\mathrm{Kp}=-0.0007$ with a reference voltage of $1.0 \mathrm{pu}$, then the magnitude of the generator output voltage before there is a very large disturbance so that the $\%$ of overshoot maximum value is not detected because the time setting is very large. The results of the simulation can be seen in Figure 4.3 below.

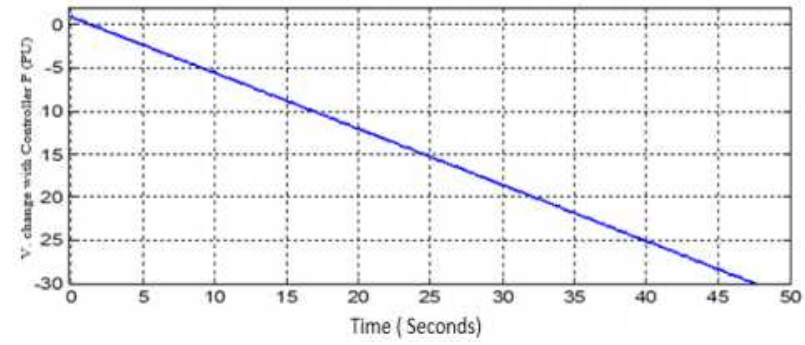

Fig. 11. Relation of Output Voltage to time with $\mathrm{Kp}=-0.0007$

b) For $K p=0$ : For $\mathrm{Kp}=0.0$ with a reference voltage of $1.0 \mathrm{pu}$, then the magnitude of the generator output voltage before there is a disturbance equal to zero so that the \% of overshoot maximum value is not detected because the settling time cannot be known. The simulation results can be seen in Figure 4.4 below.

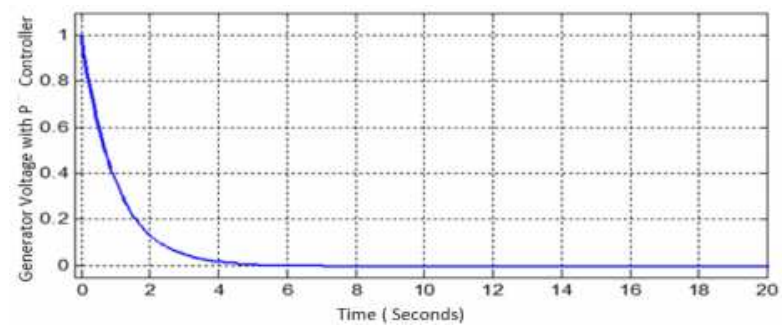

Fig. 12. Relation of Output Voltage to time with $\mathrm{Kp}=0$

c) For $K p=0.0007$ : For $\mathrm{Kp}=0.0007$ with a reference voltage of $1.0 \mathrm{pu}$, the magnitude of the Generator output voltage before there is a very small disturbance of 0.481 pu with a maximum overshoot of 3.098 and a set time of 2.9781 seconds. The results of the simulation can be seen in Figure 4.5 below:

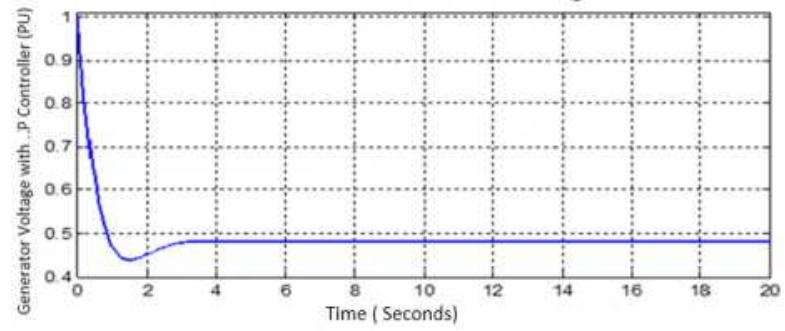

Fig. 13. Relation of Output Voltage to time with $\mathrm{Kp}=0.0007$

d) For $K p=0.0031$ : For $\mathrm{Kp}=0.0031$ with a reference voltage of $1.0 \mathrm{pu}$, then the magnitude of the generator output voltage before there is a disruption of $0.8085 \mathrm{pu}$ with $\%$ of overshoot of $25 \%$ and settling time of 2.6347 seconds. The results of the simulation can be seen in the following Figure 4.6:

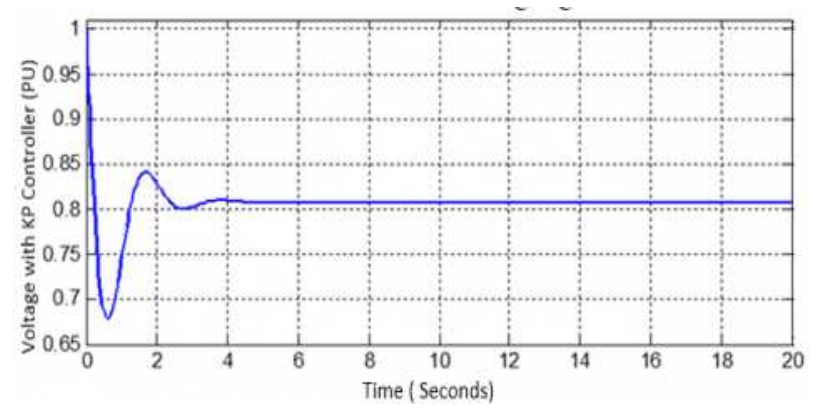

Fig. 14. Relation of Output Voltage to time with $\mathrm{Kp}=0.0031$

e) For $K p=0.005$ : For $\mathrm{Kp}=0.005$ with a reference voltage of $1.0 \mathrm{pu}$, then the magnitude of the generator output voltage before there is a very small interference for the 0.869 pu with \% of overshoot of 36.362 and settling time of 2.9204 seconds. The results of the simulation can be seen in Figure 4.7 below:

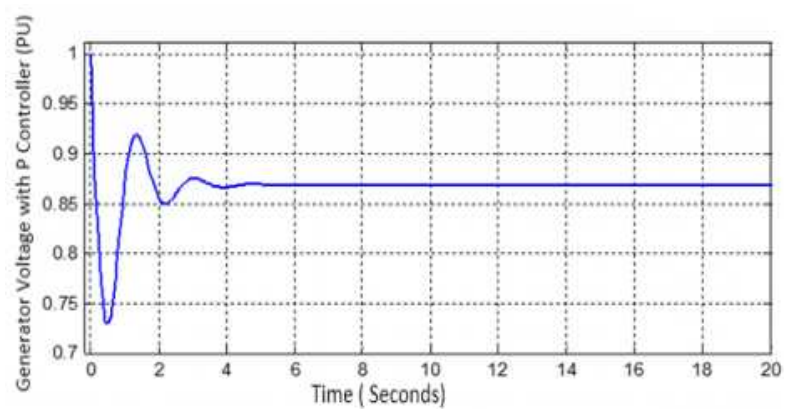

Fig. 15. Relation of Output Voltage to time with $\mathrm{Kp}=0.005$

f) For $K p=0.01$ : For $\mathrm{Kp}=0.01$ then the generator output voltage before there is a disturbance of $0.930 \mathrm{pu}$ with a $\%$ of maximum overshoot of 58.058 and a set time of 4.3774 seconds. The results of the simulation can be seen in the following Figure 4.8:

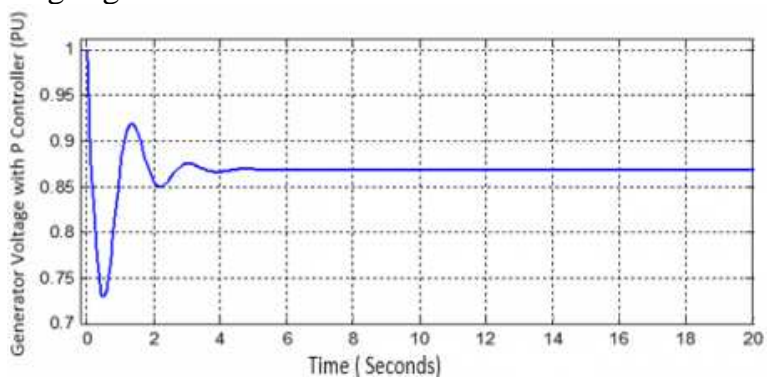

Fig. 16. Relation of Output Voltage to time with $\mathrm{Kp}=0.01$

g) For $K p=0.015$ : For $\mathrm{Kp}=0.015$, the generator output voltage before there is a disruption of $0.952 \mathrm{pu}$ with $\%$ of overshoot of 73.233 and settling time of 6.1647 seconds. The results of the simulation can be seen in the following Figure 4.9: 


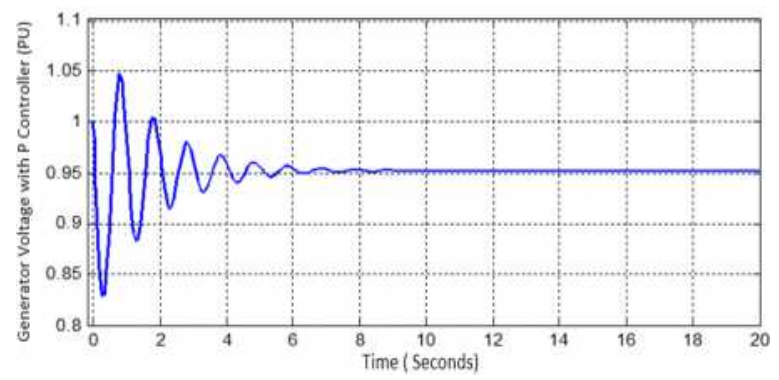

Fig. 17. Relation of Output Voltage to time with $\mathrm{Kp}=0.015$

h) For $K p=0.0156:$ For $\mathrm{Kp}=0.1564$ the generator output voltage before there is a disruption of $0.954 \mathrm{pu}$ with \% of overshoot of 75 and settling time of 6.5240 seconds. The results of the simulation can be seen in the following Figure 4.10:

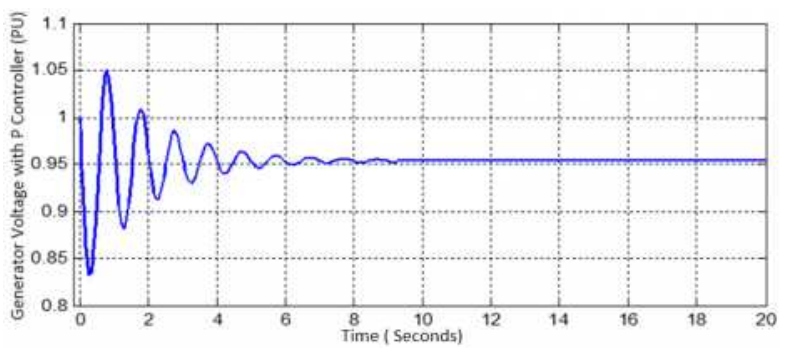

Fig. 18. Relation of Output Voltage to time with $\mathrm{Kp}=0.015645$

i) For $K p=0.02$ : For $\mathrm{Kp}=0.02$, the generator output voltage before there is a disturbance of $0.964 \mathrm{pu}$ with a maximum overshoot of 85.199 and a settling time of 11.0955 seconds. The results of the simulation can be seen in the following Figure 4.11:

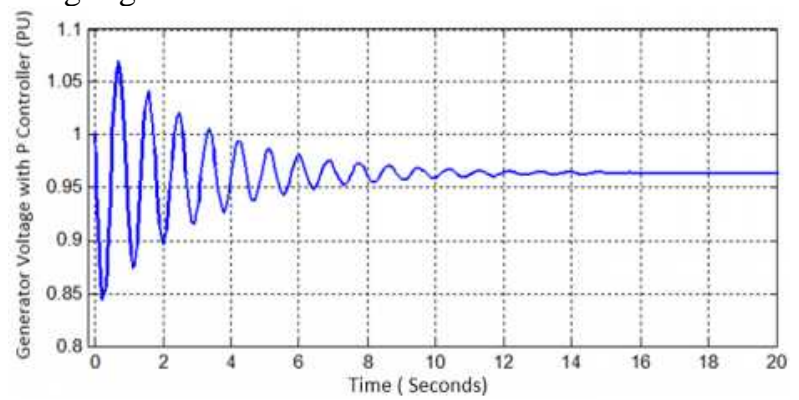

Fig. 19. Relation of Output Voltage to time with $\mathrm{Kp}=0.02$

j) For $K p=0.0268$ : For $\mathrm{Kp}=0.2689$, the generator output voltage before there is a disturbance of $0.973 \mathrm{pu}$ with $\%$ of maximum overshoot of 98.589 and settling time of 9277.26 seconds. This indicates that Oscillation is very long. The results of the simulation can be seen in the following Figure 4.12:

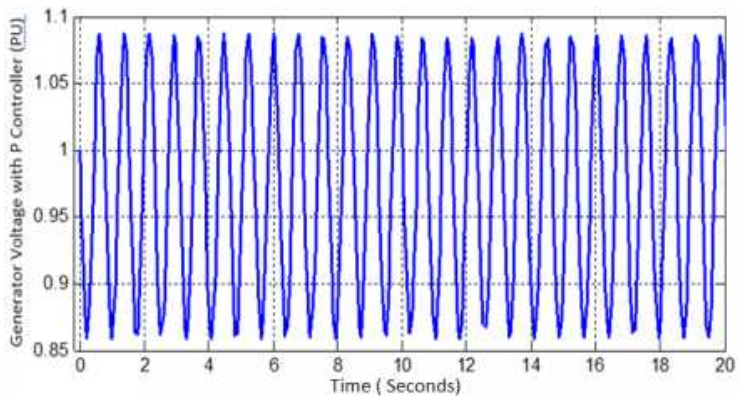

Fig. 20. Relation of Output Voltage to time with $\mathrm{Kp}=0.0268$

Based on the Kp limit calculated above, then the Kp value that matches the existing overshoot criteria as described in subchapter II.5 before, is $\mathrm{Kp}=0.00318$ with \% of maximum overshoot of 25 with settling time of 2.6347 seconds. This is seen in table 4.4 above.

\section{2) Proportional Controller $(P)$}

Previous characteristic equation obtained critical values (critical gain) by setting the value of $\mathrm{Ti}=\infty$ and $\mathrm{Td}=0$. as in table 4.1 in the previous chapter, which means using proportional control action (P) only, then increasing the constant $\mathrm{Kp}$ from 0 up to the critical value limit $\left(\mathrm{K}_{\mathrm{cr}}\right)$ (Ogata, 672).

Simulation diagram block when there is a disturbance with constant $\mathrm{Kp}=0.013446$ was illustrated in Figure 22. this explains the voltage changes that occur in the load due to changes in load reactive power $(\Delta Q)$ causing the generator output voltage to change depending on the increase or decrease in reactive power.

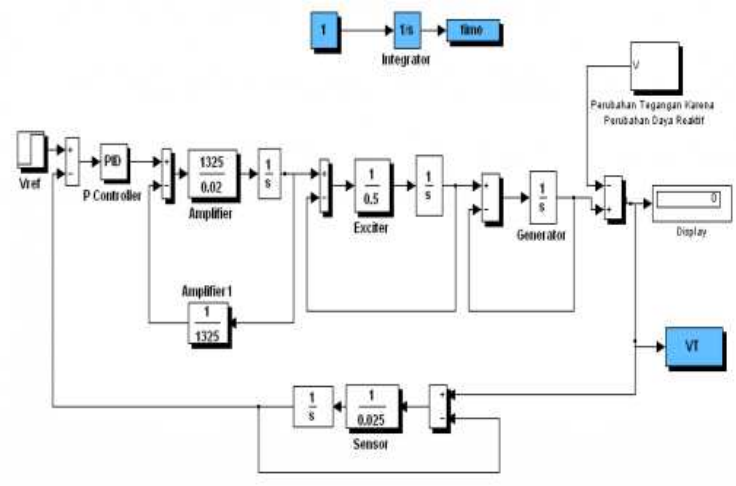

Fig. 21. Simulation of AVR with P control on fault conditions

The block diagram in Figure 22 can be simplified in the following block diagram form:

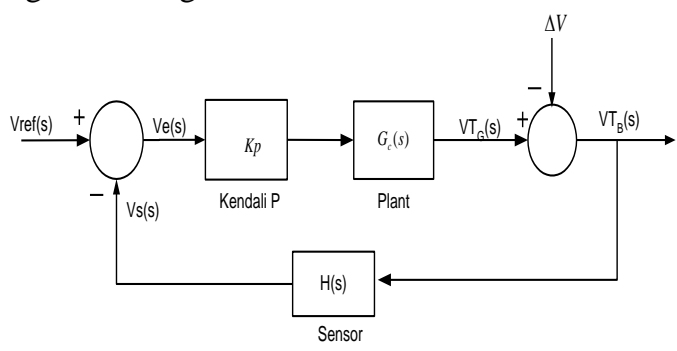

Fig. 22. Block Simplification Diagram from Figure 21 
Simulation Results with Proportional Control (P) when disruption occured.

a) Voltage change $(\Delta V)$ increased by $0.1 \mathrm{pu}$ and $\Delta V$ decreased by 0.1 pu with $K p=0.01344$ : The simulation results in Figure 24 below show the voltage change down by $0.1 \mathrm{pu}$ at 10 seconds and then increased by $0.1 \mathrm{pu}$ at the 20 seconds, then increase again at 40 seconds and lower again at 50 seconds by $0.1 \mathrm{pu}$. With the voltage change down by $0.1 \mathrm{pu}$ due to changes in load causes an increase in the generator output voltage of $0.02561 \mathrm{pu}$ and when the voltage changes increased by $0.1 \mathrm{pu}$ causing the generator output voltage to decrease by 0.025613 pu.

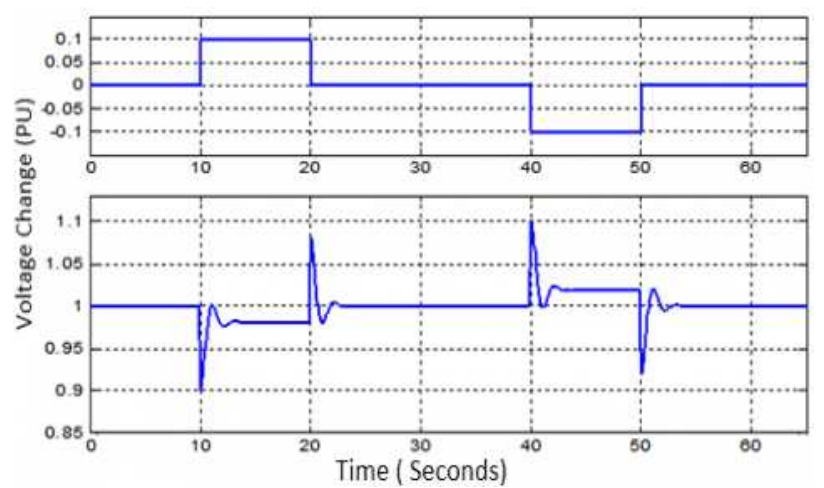

Fig. 23. Result of P Control of AVR Simulation when a fault occurs

b) Voltage Change $(\Delta V)$ decreased by 0.2 pu and $\Delta V$ increased by $0.2 \mathrm{pu}$ with $\mathrm{Kp}=0.013446$ : The simulation results in Figure 25 below show the voltage change down by 0.2 pu at 10 seconds and then up $0.2 \mathrm{pu}$ at 20 seconds and then raised again at 40 seconds and lowered at 50 seconds by 0.2 pu. With the voltage change down by $0.2 \mathrm{pu}$ due to changes in load causes an increase in the generator output voltage of $0.0462 \mathrm{pu}$ and when the voltage change increased by 0.2 pu causing the generator output voltage to decrease by $0.0462 \mathrm{pu}$.

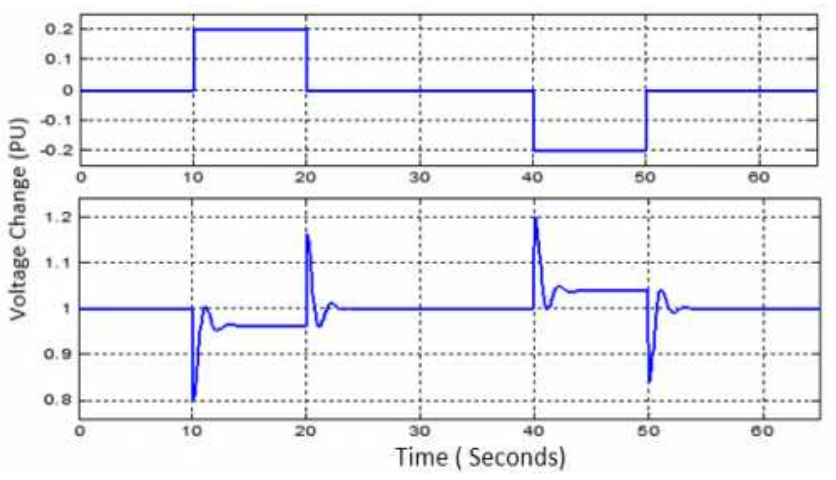

Fig. 24. Graph of Results of P control of AVR Simulation when a fault occurs

c) Voltage Change $(\Delta V)$ decreased by 0.3 pu and $\Delta V$ increased by 0.3 pu with $K p=0.01344$ : The simulation results in Figure 26 below show the voltage changes falling by $0.3 \mathrm{pu}$ at 10 seconds and then up $0.3 \mathrm{pu}$ at the 20 seconds, then raised again at 40 seconds and lowered again at 50 seconds by $0.3 \mathrm{pu}$. With the voltage change down by 0.3 pu due to changes in load causes an increase in the generator output voltage of 0.066839 pu and when the voltage changes increase by 0.3 pu causing the generator output voltage to decrease by $0.06683 \mathrm{pu}$.

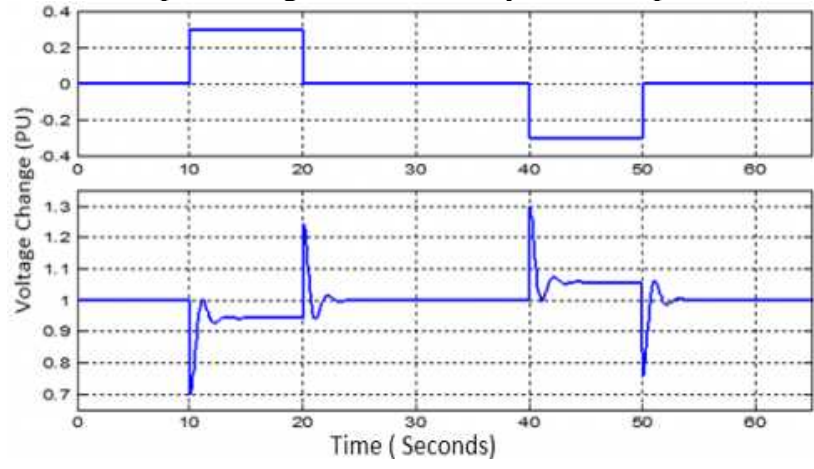

Fig. 25. Result of P Control of AVR Simulation when a fault occurs

\section{3) Proportional Integral (PI) Controller.}

As explained in the Proportional Integral (PI) controller above in determining the Kcr value, so the Kcr value in the PI controller is used to calculate the new Kp value. Simulation Results with PI Control when interference.

a) Voltage Change $(\Delta V)$ increased by $0.1 \mathrm{pu}$ and $\Delta V$ decreased by $0.1 \mathrm{pu}$ with $K p=0.01210$ and $K i=0.01883$ : The simulation results in Figure 27 below show the voltage change down by $0.1 \mathrm{pu}$ at 10 seconds and then increase $0.1 \mathrm{pu}$ at the 20 seconds, then raise again at 40 seconds and lower again at 50 seconds by $0.1 \mathrm{pu}$. With the voltage change down by 0.1 pu due to changes in load causes an increase in the generator output voltage of $0.0374 \mathrm{pu}$ and when the voltage change increased by $0.1 \mathrm{pu}$ causing the generator output voltage to decrease by $0.0374 \mathrm{pu}$

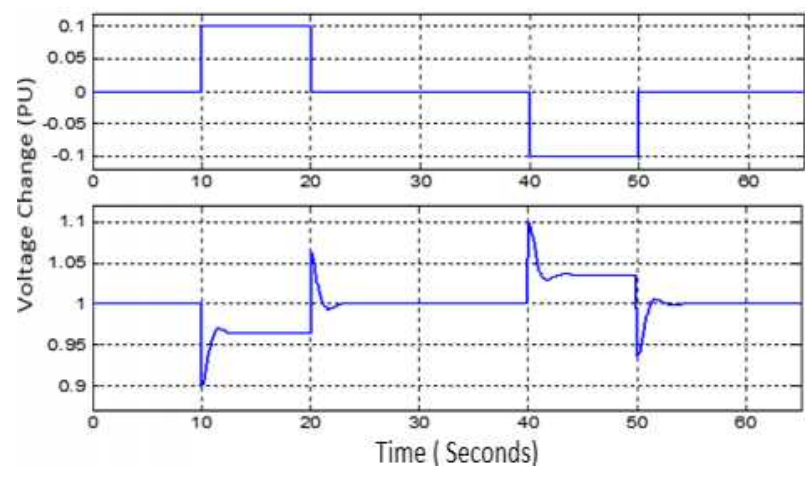

Fig. 26. Results of PI Control of AVR Simulation when a fault occurs

b) Voltage Change $(\Delta V)$ decreased by 0.2 pu and $\Delta V$ increased by $0.2 \mathrm{pu}$ with $\mathrm{Kp}=0.01210$ and $K i=0.01883$ : The simulation results in Figure 28 below show the voltage change down by 0.2 pu at 10 seconds and then up 0.2 pu at 20 seconds and then raised again at 40 seconds and lowered at 50 seconds by $0.2 \mathrm{pu}$. With the voltage change down by $0.2 \mathrm{pu}$ due to changes in load causes an increase in the generator output voltage of $0.0727 \mathrm{pu}$ and when the voltage change increases by $0.2 \mathrm{pu}$ causing the generator output voltage to decrease by $0.0727 \mathrm{pu}$. 


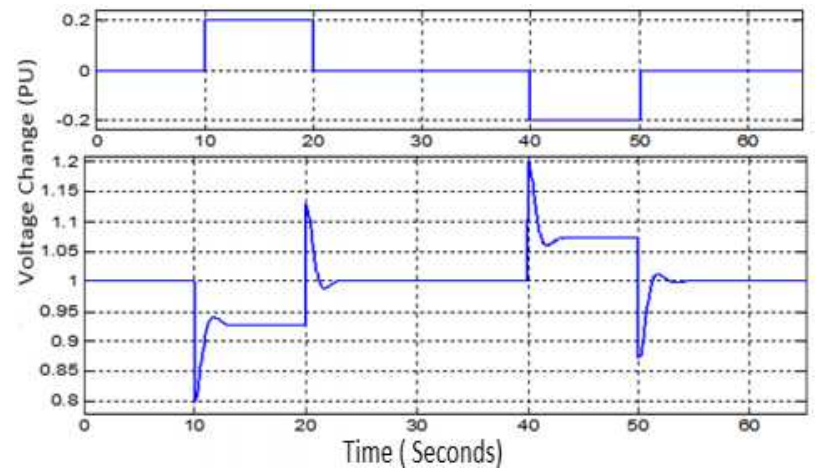

Fig. 27. Graph of PI control of AVR simulation results when a fault occurs

c) Voltage Change $(\Delta V)$ decreased by 0.3 pu and $\Delta V$ increased by $0.3 \mathrm{pu}$ with $\mathrm{Kp}=0.01210$ and $K i=0.01883$ : The simulation results in Figure 29 below show the voltage changes falling by $0.3 \mathrm{pu}$ at 10 seconds and then up $0.3 \mathrm{pu}$ at the 20 seconds then raised again at 40 seconds and lowered again at 50 seconds by $0.3 \mathrm{pu}$. With the voltage change down by 0.3 pu due to changes in load causes an increase in the generator output voltage of $0.0991 \mathrm{pu}$ and when the voltage changes rise by 0.3 pu causing the generator output voltage to decrease by 0.0991 $\mathrm{pu}$

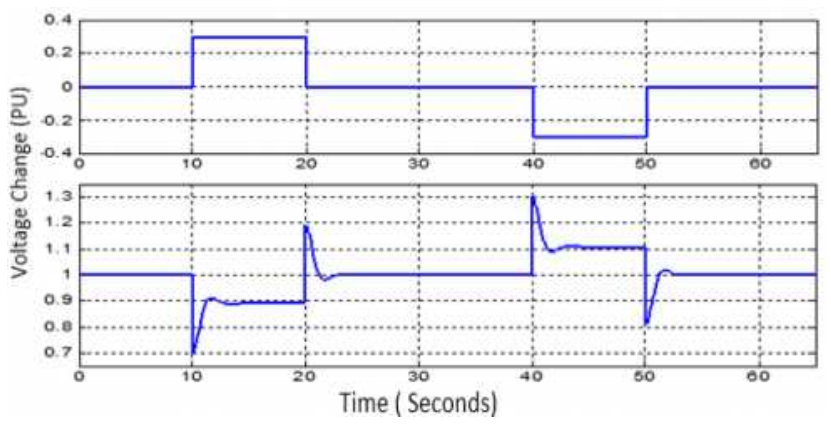

Fig. 28. Results of PI Control of AVR Simulation when a fault occurs

\section{4) Proportional Integral Derivative Controller (PID)}

The same way was conducted for PID controllers in determining Kcr and Pcr on the PI controllers above. However, the constant $\mathrm{Kp}$, Ki based on the previous table 4.1 is not the same as the PI controller, so the PID controller constant can be written as follows:

$\mathrm{Kp}=0.6 \mathrm{Kcr}$

PID Simulation Results When Interference for $\mathrm{Kp}=0.016135$, $\mathrm{Ki}=0.01815$ and $\mathrm{Kd}=0.00359$.

a) Voltage Change $(\Delta V)$ decreased $=0.1 \mathrm{pu}$ and $(\Delta V)$ increased by 0.1 pu: In the graph in Figure 30, it shows the change in voltage rises at 10 seconds and then drops at 20 seconds and is lowered again at 40 seconds and raised to 50 seconds, this can be explained that if there is a voltage change down by 0.1 , the generator output voltage experienced an increase of 0.00415 pu and when the voltage change increased by $0.1 \mathrm{pu}$ the generator voltage output increased by $0.00415 \mathrm{pu}$ from the reference voltage of $1.0 \mathrm{pu}$.

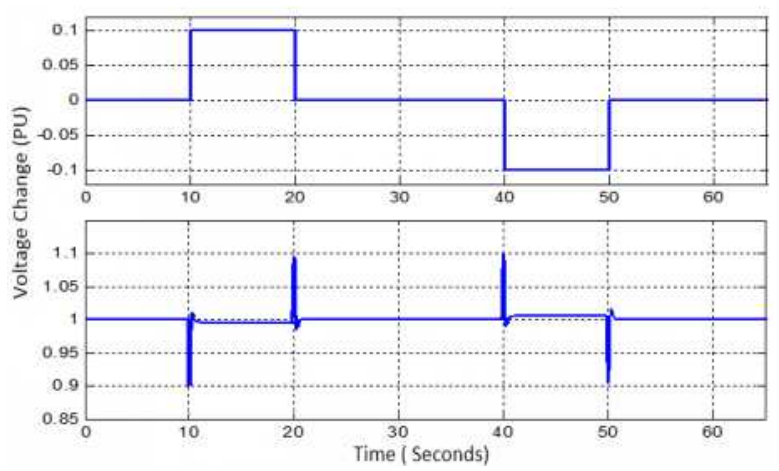

Fig. 29. Results of AVR Simulation with PID Controller when a fault occurs

b) Change in voltage drops $=0.2 \mathrm{pu}$ and increases by $0.2 \mathrm{pu}$ : In the graph in Figure 31, it shows the change in voltage rises at 10 seconds and then drops at 20 seconds and is lowered again at 40 seconds and raised to 50 seconds, this can be explained that if there is a voltage change down by 0.2 , the generator output voltage experienced an increase of $0.00831 \mathrm{pu}$ and when the voltage change increased by $0.2 \mathrm{pu}$, the generator voltage output increased by $0.00831 \mathrm{pu}$ from the reference voltage of $1.0 \mathrm{pu}$

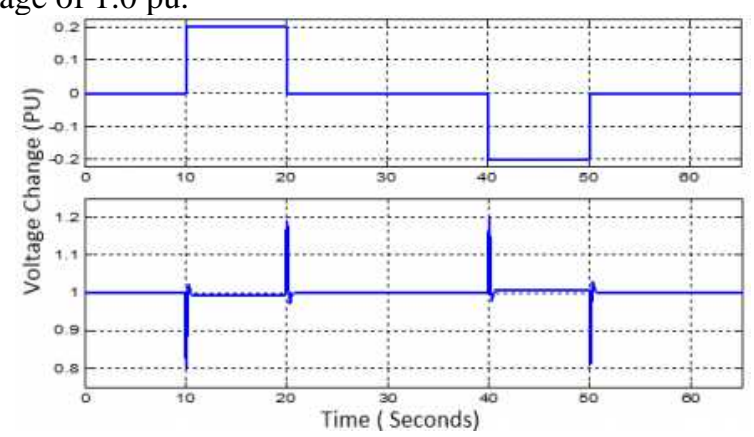

Fig. 30. Results of AVR Simulation with PID Controller when a fault occurs

c) Change in voltage drops $=0.3 \mathrm{pu}$ and rises by $0.3 \mathrm{pu}$ : In the graph in Figure 32, shows the change in voltage rises at 10 seconds and then drops at 20 seconds and is lowered again at 40 seconds and raised to 50 seconds, this can be explained that if there is a change in voltage drop of $0.3 \mathrm{pu}$, then the output voltage The generator has an increase of $0.012473 \mathrm{pu}$ and when the voltage change rises by 0.3 pu the generator voltage output increases by $0.012473 \mathrm{pu}$ from the reference voltage of $1.0 \mathrm{pu}$.

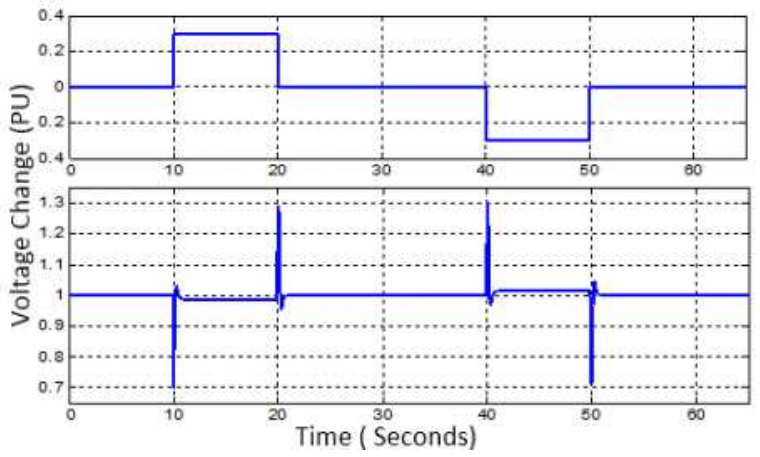

Fig. 31. Result of AVR Simulation with PID Controller when a fault occurs 
Changes in voltage up and down voltage changes affect overshoot, while the generator output voltage is quite small with short oscillations with fast stable time.

It can be seen that the PID controller is better than the P controller and PI controller on the AVR system.

\section{CONCLUSION}

Based on the simulation results and the discussion in the previous chapter, the following can be concluded:

1. The performance of AVR with $\mathrm{P}$ control in normal conditions produced oscillation at work and required time to return to its stable voltage, as well as when the load changed (interference), AVR with $\mathrm{P}$ and PI controllers produced oscillations based on voltage changes due to changes in the given reactive load. This required time for $\mathrm{P}$ controller $=$ 2.63476 seconds and PI Controller $=2.25754$ seconds with an overshoot of $25 \%$ in returning the voltage to the stable point. The oscillations occured can be suppressed by sampling so that the initial value of the graph started from $1.0 \mathrm{pu}$.

2. The PID in helping AVR performance was obtained by setting the root value in the characteristic equation so that the constant $\mathrm{Kp}=0.016135$ was obtained, $\mathrm{Ki}=0.01815$ and
$\mathrm{Kd}=0.00359$. This value was able to maintain the generator voltage output at the time of interference with settling time (ts) of 0.89594 and maximum overshoot of $25 \%$.

\section{ACKNOWLEDGMENT}

We thank Universitas Musamus for facilities, supports, and publications.

\section{REFERENCES}

[1] V. Singhal, "Design and Performance Analysis of Tuning Conventional Controllers and Fuzzy controller PID approach for Automatic Voltage Regulator,” Int. J. Mod. Trends Eng. Res., vol. 4, no. 1, pp. 269-277, 2017.

[2] P. Kundur, "[Prabha Kundur] Power System Stability And Control.pdf." McGraw Hill.Inc, New York, 1993.

[3] H. E. Patoding, E. T. Lobo, and M. Sau, "Modeling Control of Automatic Voltage Regulator With Proportional Integral Derivative," pp. 241-245, 2015.

[4] K. Ogatha, "modern-control-engineering-3rd-ed-ogataprentice-hall.pdf." Pretince Hall, New Jersey, 1997.

[5] S. Testouri, K. Saadaoui, and M. Benrejeb, "A Particle Swarm Optimization Approach for Optimum Design of First-Order Controllers in TCP/AQM Network Systems," Int. J. Comput. Appl., vol. 45, no. 7, pp. 31-38, 2012. 